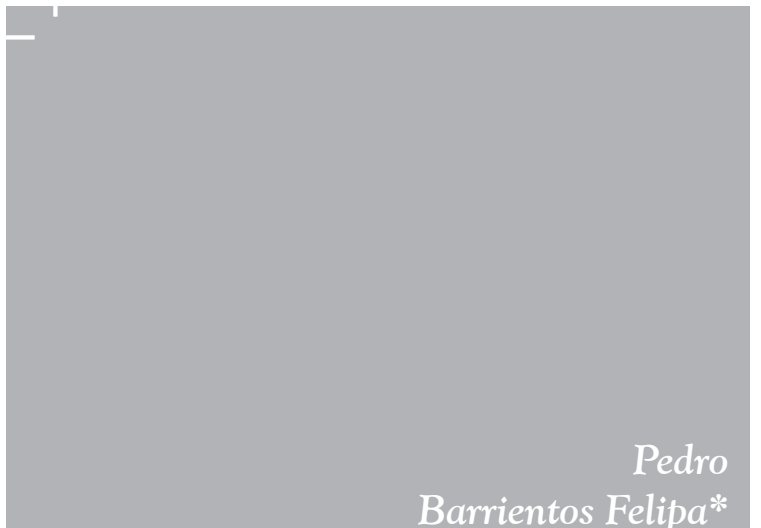

Universidad Nacional Mayor de San Marcos, Lima, Perú

Recibido: 16 de agosto de 2013 Concepto de evaluación: 8 de febrero de 2014 Aprobado: 17 de marzo de 2014

Artículo de reflexión DOI: $h$ ttp://dx.doi.org/10.14718/ revfinanzpolitecon.2014.6.1.6

(c) 2014 Universidad Católica de Colombia. Facultad de Ciencias Económicas y Administrativas. Todos los derechos reservados.

*Economista magíster en Concentración en Marketing, candidato a doctor en Administración de Negocios Globales en la Universidad Ricardo Palma, Lima,

Perú. Profesor principal

de la Facultad de Ciencias Económicas y miembro del Instituto de Investigaciones

Económicas de la Universidad

Nacional Mayor de San Marcos, Lima, Perú.

Dirección de correspondencia: Ciudad Universitaria,

edifico Facultad de Ciencias Económicas, Avenida Universitaria Lima, 1, Lima, Perú. Correo electrónico: pbarrientosf@unmsm.edu.pe

\section{El desarrollo de la marca país: base para posicionarse a través de las exportaciones no tradicionales}

\section{RESUMEN}

En el mercado internacional existen países que tienen características similares de oferta; por tanto, es conveniente establecer una ventaja sobre los competidores de manera que asegure y fortalezca el crecimiento económico. Los compradores buscarán los productos que tengan los mejores atributos, tangibles e intangibles, que aseguren la satisfacción de sus necesidades. El establecimiento de una marca país, entonces, se hace conveniente, para lo cual es necesario realizar una serie de actividades (diferenciación) para generar un país (marca) posicionado. La marca es consecuencia de diversas actividades nacionales. En tal sentido, se identifica la connotación que tiene la marca país en el comercio internacional, y las actividades necesarias para establecer una marca país sostenible. Establecer una marca es un esfuerzo que en estos momentos están realizando muchos países; así mismo, existen una diversidad de esfuerzos para medir si se tiene clara una posición y lo que es necesario para que se consolide.

Palabras clave: marketing país, marca país, economía internacional, marketing internacional, competitividad internacional, Perú.

JEL: M31, M16

\section{The Development of a National Brand:}

Fundaments in Positioning through Non-traditional Exports

\section{ABSTRACT}

Many countries in the global market offer similar things, so it is important to increase competitivity in a way that assures and strengthens economic growth. Buyers are constantly on the lookout for better products, products that better meet their needs, so good branding is very important for a country. The creation of a national brand by establishing what makes us different is important for better positioning within the market and a better national brand. The study looks at the importance of national branding in today's global market and strategies to ensure that the brand is sustainable. Many countries are today working on their national brand and there exist many strategies for assuming a clear position in the market and ways in which this position can be strengthened.

Keywords: Country marketing, national brand, global economy, global competitivity, Peru. 


\section{O desenvolvimento da marca país: base para se posicionar por meio das exportações não tradicionais}

\section{RESUMO}

No mercado internacional, existem países que têm características similares de oferta; portanto, é conveniente estabelecer uma vantagem sobre os concorrentes de maneira que garanta e fortaleça o crescimento econômico. Os compradores procurarão os produtos que tiverem os melhores atributos, tangíveis e intangíveis, que garantam a satisfação de suas necessidades. $\bigcirc$ estabelecimento de uma marca país, então, faz-se conveniente e, para isso, é necessário realizar uma série de atividades (diferenciação) para gerar um país (marca) posicionado. A marca é consequência de diversas atividades nacionais. Nesse sentido, identifica-se a conotação que a marca país tem no comércio internacional e as atividades necessárias para estabelecer uma marca país sustentável. Estabelecer uma marca é um esforço que nestes momentos estão realizando muitos países; além disso, existe uma diversidade de esforços para medir se se tem clara uma posição e o que é necessário para que se consolide.

Palavras-chave: marketing país, marca país, economia internacional, marketing internacional, competitividade internacional, Perú. 


\section{INTRODUCCIÓN}

El crecimiento económico de Perú en los últimos años, expresado a través del Producto Bruto Interno $(\mathrm{PBI})$, es una muestra de los que está ocurriendo a nivel macroeconómico en el Perú: hay una orientación mayor hacia el mercado externo. Con el proceso de globalización existe cada día una mayor relación e interdependencia entre los países que son actores de este proceso y participan en diferentes condiciones; unos tienen mayor ventaja que otros. Ahora, es la aceptación de una competivididad dinámica un factor crucial para obtener ventajas en el comercio internacional.

En el comercio internacional existen muchos países vendedores y pocos compradores para todo el volumen que los países están dispuestos a ofrecer. Lo enunciado adquiere valor con lo que expone Czinkota y y Ronkainen (2006, p. 15): "Desde una perspectiva global, Estados Unidos ha ganado reconocimiento como mercado para el mundo, pero ha perdido parte de su importancia como proveedor mundial". Ahora hay más países proveedores; han ingresado nuevos participantes de gran tamaño (China, India, Brasil) que buscan un lugar en el comercio internacional y que como dicen los autores citados actúan agresivamente y le dan así una mayor dináimica al comercio mundial.

De ahí que sea importante que cada país posea una ventaja sobre los otros países vendedores, una ventaja sostenible que permita asegurar la venta de su producción en el mercado internacional, sean bienes o servicios. La generación de esa ventaja hace sostenible la participación en el mercado internacional en mejores condiciones, lo cual se ve reflejado en los resultados de la Balanza Comercial. Cuando se compite internacionalmente el éxito exige que las empresas transformen sus posiciones nacionales en posiciones internacionales.

La preocupación de los países es cómo mantener una oferta sostenible de productos que haga posible la lealtad de sus compradores internacionales en el largo plazo. Algunos países tienen esta relación de confianza de sus compradores a nivel internacional, que no solo asegura la venta de productos sino que también influye en las posibilidades de inversión extranjera directa (IED) y de visitantes y residentes, personas y organizaciones. Son países que se comprometen con una serie de medidas internas que les favorezcan a ellos mismos, y allí participan activamente el Estado, los inversionistas, los proveedores y los consumidores finales.

Hay trabajos como los de Porter (1990), en los cuales se indica que los países tienen éxito en el mercado si sus circunstancias nacionales proporcionan un ambiente que apoye el mejoramiento y la innovación. Kotler, Jatuspritak y Maesincee (2007) presentan un enfoque sobre el crecimiento económico, basándose en los conceptos del marketing; aquí se encuentra la asociación del marketing país. El crecimiento del mercado global obliga a que los países miren más allá del buen estado de la economía doméstica. Los gobernantes deben enfocar sus esfuerzos a diseñar políticas capaces de genrar, tanto crecimiento económico, como el desarrollo nacional. Un factor que puede apoyar esta sostenibilidad es el establecimiento de una marca país, que se debe reconcer como parte de una estrategia marketing país.

\section{LA MARCA PAÍS Y LA COMPETITIVIDAD}

\section{El concepto de marca}

La American Marketing Association' define marca (brand) como un "Name, term, design, symbol, or another feature that identifies one seller's good or service as distinct from those of other sellers"2. EI diseñador de la estrategia de marketing, el mercadólogo, considera que es la base sobre la cual se construye la imagen de un producto para que este sea aceptado por los consumidores objetivo. La marca va más allá de un logotipo, es un concepto $y$, por lo tanto, es algo abstracto, y para hacerlo real se consideran factores que exceden lo que es

1 American Marketing Association. (Diccionario). Recuperado de http://www.marketingpower.com/_layouts/Dictionary. aspx?dLetter $=\mathrm{B}$

2 Traducción del autor del artículo: “Un nombre, término, signo, símbolo u otra característica que identifica las productos de un vendedor y los distingue de los competidores". 
un logotipo o un color. Si hay una estrategia relacionada, esto implica que existe una serie de pasos planificados previos.

Es complicado establecer un concepto de marca o entender qué es esta última. En el lado de los consumidores se cita que cuando un producto está posicionado ${ }^{3}$, es decir, que tiene la preferencia de los compradores ante diversas ofertas, es un producto de marca, o simplemente es una marca. Para el consumidor un producto de marca le da valor. Por el lado de los productores, cuando lanzan al mercado un nuevo producto y lo identifican con un nombre, color, símbolo, forma de envase o la suma de todos ellos, están estableciendo una marca; es parte del inicio del desarrollo de un producto, todo tiene un nombre. Sin embargo, de esta conceptualización, queda claro que lo que tiene marca es porque es diferente y los compradores lo buscan, y los fabricantes hacen todo lo posible por apoyar o influir en la decisión del mercado meta. La marca hace más fácil la comercialización.

Lo mismo puede ocurrir con los inversionistas cuando deciden identificar países para realizar sus proyectos. Invertir está relacionado con el riesgo, por lo tanto el empresario decide minimizar su riesgo y obtener el máximo rendimiento posible; busca a aquellos países que así lo permitan a no ser que tenga por objetivo especular asumiendo mayor riesgo. Por su parte, los países también consideran que los inversores, locales y extranjeros, se establezcan y desarrollen en su territorio y se dan cuenta de que hay que reunir ciertas condiciones para que esto ocurra. Son estas condiciones las que el gobierno a través de la política nacional debe crear para atraerlos. Esto es lo que va a generar actividades relacionadas con la marca país, dentro de una estrategia marketing país. Similar situación se presenta con los visitantes (turistas y potenciales residentes, así como organizaciones), pues al tomar una decisión realizan una evaluación del riesgo que ellos asumen al visitar un país determinado: aquel que le ofrezca mayor valor es el elegido. Puede entenderse y construir una marca país como un proceso de largo aliento.

3 Se relaciona con el concepto de posicionamiento. 118

\section{El significado de una marca país}

Marca país quiere decir considerar el esfuerzo total de un país como organización, no en determinadas actividades, que de por sí es una limitación, ya que implica exclusión de otros y fortalecimiento de algunos. Establecer una marca país como parte de una estrategia de marketing país es un proceso de creación de una oferta de productos tangibles más intangibles. Implica disputar competitivamente. Hay varios proveedores para la satisfacción de la demanda, actual y potencial. La experiencia de otros países que ya establecieron una marca país han resuelto en gran medida problemas estructurales de su comunidad como la calidad de la educación, aspectos sanitarios de los menos favorecidos, la mejora real del ingreso familiar, infraestructura y otros factores que convierten una marca país en algo sostenible.

Abó (2010) cita que la marca tiene el desafío de crear una serie de asociaciones positivas en el consumidor objetivo de manera sostenida en el tiempo. Es un esfuerzo organizacional porque perdura representando valor, cultura y personalidad. Esto se hace especial cuando se trata de la marca país. Así mismo, Abó opina que cuando se citan productos (bienes o servicios) de un país determinado se deben distinguir dos conceptos: país de origen y marca de origen. El autor citado menciona que "El país de origen (lugar donde fue fabricado o generado el producto) impacta en el mercado de acuerdo a las percepciones que el consumidor final tiene de las características del país y su asociación con la calidad de los productos fabricados en el mismo. Se trata del sello que acompaña a los productos como 'Made in...'"' (p. 2).

La marca de origen (país asociado a la marca de un producto) se refiere al país que el consumidor asocia a un determinado producto independientemente de donde este es fabricado. La marca de origen es utilizada como forma de aumentar el valor percibido por el cliente cuando el país tiene una buena imagen asociada a las características del producto ofrecido. La marca de origen es indudablemente un factor fundamental para el consumidor. Sin embargo,

Finanz. polit. econ., ISSN 2248-6046, Vol. 6, No. 1, enero - junio, 2014, pp. 115 - 140 Edición Especial - Economía Regional 
EL DESARROLLO DE LA MARCA PAÍS: BASE PARA POSICIONARSE A TRAVÉS DE LAS EXPORTACIONES NO TRADICIONALES

aunque la marca de origen es importante para el consumidor, el país de origen influye en gran medida, pues no es lo mismo para el consumidor un producto de una marca determinada producido en Japón que fabricado en Polonia.

La marca país influye en dos dimensiones: como marca de origen, un país generará por medio de su imagen una ventaja o una desventaja para una empresa internacional en fabricar en ese país; como país de origen, la imagen de ese país ayudará o perjudicará a la promoción de los productos y servicios domésticos en su promoción en el extranjero. Abó, (2010, p. 4) indica que como resultado de la aplicación de estas dos variables un país se ve favorecido por lo siguiente:

1. Favorecería a las marcas intencionales a ser producidas en el país.

2. Atraería inversión directa extranjera (IDE).

3. Favorecería la introducción de marcas domésticas en el exterior y potenciaría las exportaciones.

Sánchez Cáceres (2011) explica respecto a la construcción de una marca país como un proceso que abarca tiempo, trabajo en equipo y voluntad de llegar a un final, cuyo resultado es favorable para el país. Pero también exige transformaciones, porque puede ocurrir que solo sale favorecido un sector y quedan rezagados a otros. Establecer una marca es desarrollar una estrategia de posicionamiento, a través de diversas actividades que hace diferentes y mejores de otros que compiten por el mismo mercado. Sánchez Cáceres lo explica de la manera siguiente:

De acuerdo a la experiencia internacional, la creación y conceptualización de una marca país debe partir de la definición de una estrategia de posicionamiento que sea construida, articulada e implementada por el conjunto de actores que la representará tanto desde el sector público como del privado y que le permita, entre otras cosas, potenciar y garantizar su permanencia a largo plazo en el contexto global. Su éxito dependerá por tanto de la capacidad innovadora de sus ejecutores al momento de determinar cuál es la imagen actual del país y cuál se desea proyectar, así como la delimitación del rol que cada uno de sus actores de manera colectiva e individual, debe jugar (2011, p. 13).

Al Perú le interesan las iniciativas de marca país de diferentes países, sin importar el nivel de crecimiento económico, porque es una oportunidad de aprender y estar en mejor capacidad de emprender acciones futuras contra otros países en aspectos comerciales, pero también en lo que corresponde al manejo de la economía nacional, el desarrollo de la industria manufacturera, el turismo, la cultura y otros aspectos en los cuales se pueden desarrollar ventajas. Al desarrollar una estrategia sólida, coherente y sostenible se puede posicionar a Perú en el exterior. Es un esfuerzo sistémico, donde las organizaciones públicas y privadas conocen las acciones que tienen que realizar y la importancia de sus actividades en el establecimiento de la marca, lo que se realiza dentro de un presupuesto establecido y en un tiempo determinado.

¿Sobre qué base puede un país desarrollar la marca país? Debe comenzarse con lo que expresan Ramos y Noya (2006, p. 5) "la marca país no puede quedar librada al azar ni estar atada a percepciones coyunturales que, por cierto, no siempre son favorables. Si a la marca no se la diseña y se la administra, se dispersa espontáneamente". El esfuerzo que hace un país por lograr la atención de los compradores extranjeros es hoy en día uno de los temas más mencionados en las estrategias de marketing internacional, y se convierte así en un tema de investigación, debido a que esto tiene consecuencias en el desarrollo de un país.

López Da Silva (2010, p. 335) menciona pruebas al respecto que deben ser consideradas en las actividades de marketing de un país teniendo en cuenta que lo que realice u ocurra dentro 
de sus fronteras tiene efecto positivo o negativo. El efecto tiene influencia en el mercado objetivo, actual y potencial. De ahí la importancia de lograr la percepción favorable del "hecho en...", "realizado por...", "ubicado en..." y otros similares. Es esto lo que busca lograr un país en una economía donde la competitividad de sus actividades sociales es la característica que permite avanzar. López Da Silva (2010) menciona la investigación de Samiee (1994, citado por Da Silva, 2010), quien relaciona las causas y los efectos del made in. Según su modelo, el efecto made in viene determinado por tres grupos de factores:

1. Factores del consumidor (notoriedad de la marca, participación en el proceso de compra y tendencias etnocéntricas).

2. Factores del producto y del mercado (características y tipo de producto y competencia de otros países).

3. Factores del entorno del país (nivel de desarrollo del país de origen de la marca, similitud política, social y cultural del país de origen de la marca con el país de destino).

Estos factores determinan el grado de importancia del país de origen del producto o servicio y el efecto positivo o negativo en la decisión de compra; sin embargo, hay limitaciones para que el concepto se desarrolle. La actuación fragmentada de los países (cada región o ciudad actúa por su lado) o la ausencia de un comportamiento uniforme de todas ellas atentan contra el establecimiento de una marca única, y se genera así una oferta dispersa. Ante tal ocurrencia, los gobiernos de los países crean un organismo que custodie el desarrollo de la marca país y que el comportamiento de las ciudades, organismos públicos y privados, e incluso productos, tenga una sola oferta y permita cumplir el objetivo. Así es como ocurre en el Perú, este papel le corresponde a la Comisión de Promoción del Perú para la exportación y el Turismo (Promperu).

Yagüez (2001) destaca la importancia del esfuerzo que hacen los gobiernos por establecerse como una marca, siguiendo los mismos principios que se adoptan en el marketing empresarial. También explica que los países tienen que competir con otros países y esta competencia debe ser administrada adecuadamente para obtener las ventajas que son necesarias para una mejor penetración en el mercado. Así mismo, propone que se establezcan los parámetros necesarios para realizar una comparación competitiva y en este caso el Nation Brand Index 4 utiliza como indicadores el Gobierno, la inversión, el turismo, las exportaciones, la cultura y su gente. La idea principal de Yagüez puede considerarse como sigue:

Todos somos conscientes de la importancia que la marca país tiene en un mundo globalizado. La manera en la que es percibido un país puede influir en el éxito de sus negocios, el comercio y el turismo, así como en sus relaciones culturales o diplomáticas con otras naciones. La marca país es un bien intangible de cualquier nación, para que la gestión y la situación económica es de capital importancia pero no suficiente para posicionarte en un puesto privilegiado en el ranking mundial de marca país. La gestión de la marca país no debe tratarse como la gestión de cualquier otra marca, pues se trata de una cuestión algo más compleja, una marca compuesta por una multiplicidad de factores en cuya proyección interactúan agentes políticos, económicos y sociales (2001, p. 20).

\section{La teoría del comercio internacional y la marca país}

El análisis de las actividades de comercio internacional, como el establecimiento de una marca país,

$4 \quad$ GFK publicado en http://www.gfkamerica.com/practice_areas/roper_pam/nbi_index/index.en.html 
implica la revisión de los modelos económicos que explican la razón de porqué ocurre tal situación, relacionando la importancia que tienen las actividades que son parte de su cadena de valor, ya que estas trascienden las fronteras del país y que además trascienden en el ámbito cultural, político, tecnológico, entre otros. El establecimiento de una marca país y todo esfuerzo que se realice tiene que hacer modificaciones en la forma de hacer comercio internacional entre los países y afecta la realidad de los que son parte del intercambio y que aunque no lo hace de manera similar en todos los países sí ocurre, porque hay asimetrías económicas que afectan la estrategia de marketing internacional y la competitividad.

Las teorías o modelos que sustentan el desarrollo comercial internacional explican que un mayor comercio está relacionado al crecimiento económico. Las teorías tratan de identificar las razones de esta relación. Todos los países tienen activos, con diferentes niveles de productividad; los principales activos se relacionan con el recurso humano, la tecnología utilizada, los recursos naturales y las posibilidades financieras. Son estas fuerzas las que permiten llevar a cabo los intercambios y competir en el exterior, ya que los países con economías abiertas tienden a ser compradores, pero también ofertantes de sus recursos. Son estas fuerzas las que realizan un aporte para establecer la marca país. Es todo un proceso que se ha llevado a través de siglos y que los tratadistas de la economía han sabido explicar la relación comercio internacional y su consecuencia: la marca país.

El estudio más reciente es el aporte de Porter (1990), cuya tesis sostiene que existen cuatro atributos principales de una nación que moldean el contexto en el que las empresas locales compiten, y estos atributos promueven o impiden la creación de una ventaja competitiva o son competitivos. Es un punto de vista para realizar el análisis de cómo es que se puede iniciar un proceso de marketing país, siendo su consecuencia el concepto de marca país. Estos atributos son los que se mencionan a continuación y a los cuales deben incluirse el papel del Gobierno y los hechos fortuitos (la oportunidad):
- Dotación de factores: la posición nacional en los factores de producción como la mano de obra calificada o la infraestructura necesaria para competir en una industria determinada.

- Condiciones de la demanda: la naturaleza de la demanda nacional para el producto o el servicio de una industria determinada.

- Industrias conexas e industrias de apoyo: la presencia o ausencia dentro de una nación de industrias proveedoras y conexas que sean internacionalmente competitivas.

- Estrategia, estructura y rivalidad de las firmas: las condiciones de una nación que rigen la forma como las compañías se encuentran creadas, organizadas y dirigidas, así como la naturaleza de la rivalidad nacional.

Porter (1990) sostiene que dos variables adicionales pueden influir en el diamante nacional de manera importante: el Gobierno y la oportunidad. El Gobierno, mediante las políticas que establezca, puede disminuir o incrementar la ventaja nacional. Este análisis es importante en la consideración de una marca país. La oportunidad, como una innovación importante, crea variaciones que pueden descongelar o darle nueva forma a la estructura de una industria $y$, por lo tanto, conferir la oportunidad para que las firmas de un país suplanten las de otro país.

La idea central de la propuesta de Porter (1990) es que el éxito de un país en determinada industria se debe a la interrelación de los factores citados. Los países tienen éxito en una industria determinada si sus circunstancias proporcionan un ambiente que apoye el mejoramiento y la innovación. Hay que considerar que cuando se compite internacionalmente, ocurre la exigencia de que las empresas transformen sus posiciones nacionales en posiciones internacionales. Las empresas de éxito internacional son espectadoras activas en el proceso de crear ventaja competitiva; se ubican 
en un proceso continuo de buscar nuevas ventajas y de lucha para protegerlas de sus competidores.

El éxito es sostenible cuando un país ha superado sus problemas estructurales, esto es lo que genera una marca y para lo cual se necesita un esfuerzo conjunto en el interior del país que busca consolidarse en el mundo globalizado. La estrategia de marketing país debe tomar en cuenta que la labor promocional es un paso para desarrollar la marca país; es la parte visible de la estrategia. En la estrategia global de un país es importante superar problemas estructurales y coyunturales que consoliden la marca y que minimicen el riesgo de los mercado objetivo; de ahí lo complicado de llevar a cabo una acción de marketing en un país.

\section{El riesgo país y la marca país}

Un país se convierte en marca dependiendo del riesgo que implique para los demandantes. El concepto de marca se asocia a posicionamiento, lo cual ocurre porque un país determinado otorga beneficios a su consumidor, actual o potencial, y ante tal circunstancia toma decisiones de hacer negocios con el país. El concepto de riesgo se relaciona con la vulnerabilidad que un país representa para su consumidor, puede ser un riesgo alto acudir a determinado país, comprar bienes o servicios del país determinado o puede ser todo lo contrario. Aquel país que otorga mayor valor (menor riesgo) para el cliente es el elegido y si está relación se hace permanente se genera la marca como concepto de confianza. Esta idea tiene una mejor exposición con lo que manifiesta Otero (2011, p.17):

Los países que han logrado crear percepciones positivas tienen ventajas competitivas que añaden valor a sus productos o servicios. Por el contrario, cuando no hay percepciones, o son negativas, la penetración y permanencia de sus ofertas y servicios tienen que superar un obstáculo que puede ser tan alto como cualquier barrera técnica o comercial.
Desde el punto de vista empresarial, la creación de una marca potente y que transmita confianza a sus consumidores o clientes requiere un importante esfuerzo e inversión, así como una constante dedicación, ya que puede llevar muy poco tiempo destruir aquello que has conseguido con tanto esfuerzo, e incluso esa pérdida de confianza pueda acabar con la desaparición de la marca.

De ahí la importancia de considerar al momento de diseñar una estrategia marca país el riesgo que el país representa. Hay un riesgo país y se puede definir como la medida de la probabilidad de que un país incumpla las obligaciones financieras correspondientes a su deuda externa. Un término asociado a riesgo países es el de riesgo soberano, que da lugar a calificaciones crediticias (rating crediticio) que agencias calificadoras de riesgo internacionales elaboran respecto a las deudas públicas de los países.

Una explicación acertada, en cuanto al riesgo país, y que es indicador de cómo construir una marca país, es lo que se expresa a continuación:

El rating indicará a los potenciales inversionistas la "calidad" de la deuda de cada país, y eventualmente es un elemento para la determinación del rendimiento exigible a esa inversión. Dada la tasa de interés especificada en los instrumentos de deuda (bonos), el precio de dichos bonos equiparará la tasa de interés con el rendimiento deseado. Esta relación tasa de interés-retorno es esencial para comprender el indicador de Riesgo País Un breve, y no exhaustivo, repaso a los elementos que usualmente consideran las Agencias Calificadoras de Riesgo para otorgar su rating nos dará una idea de esa complejidad comentada en la introducción de esta nota.

- Crecimiento Actual y Proyectivo

- Situación Fiscal 
- Sostenibilidad de la Deuda Externa

- Situación Externa

- Sostenibilidad de la Cuenta Corriente de la Balanza de Pagos

- Nivel de Reservas Internacionales

- Inflación Actual y Presiones Inflacionarias

- Estructura y Estabilidad Social

- Estructura y Estabilidad Política (Revista de la Universidad San Ignacio de Loyola, s.f).
Los factores anteriores son parte de los elementos que permiten a un país diferenciarse de otros y así establecerse como marca. A nivel macro, para este ejemplo, se observa que la calificadora toma en cuenta siete factores macroeconómicos, que los inversionistas consideran para tener confianza al momento de tomar decisiones. Hay otros factores que el mismo país debe considerar para lograr un posicionamiento sostenido, lo que se representa como resultado en una estrategia marketing país. Los potenciales clientes se sentirán

Figura 1.

Factores de diferenciación para establecer un posicionamiento

(aspectos macroeconómicos)
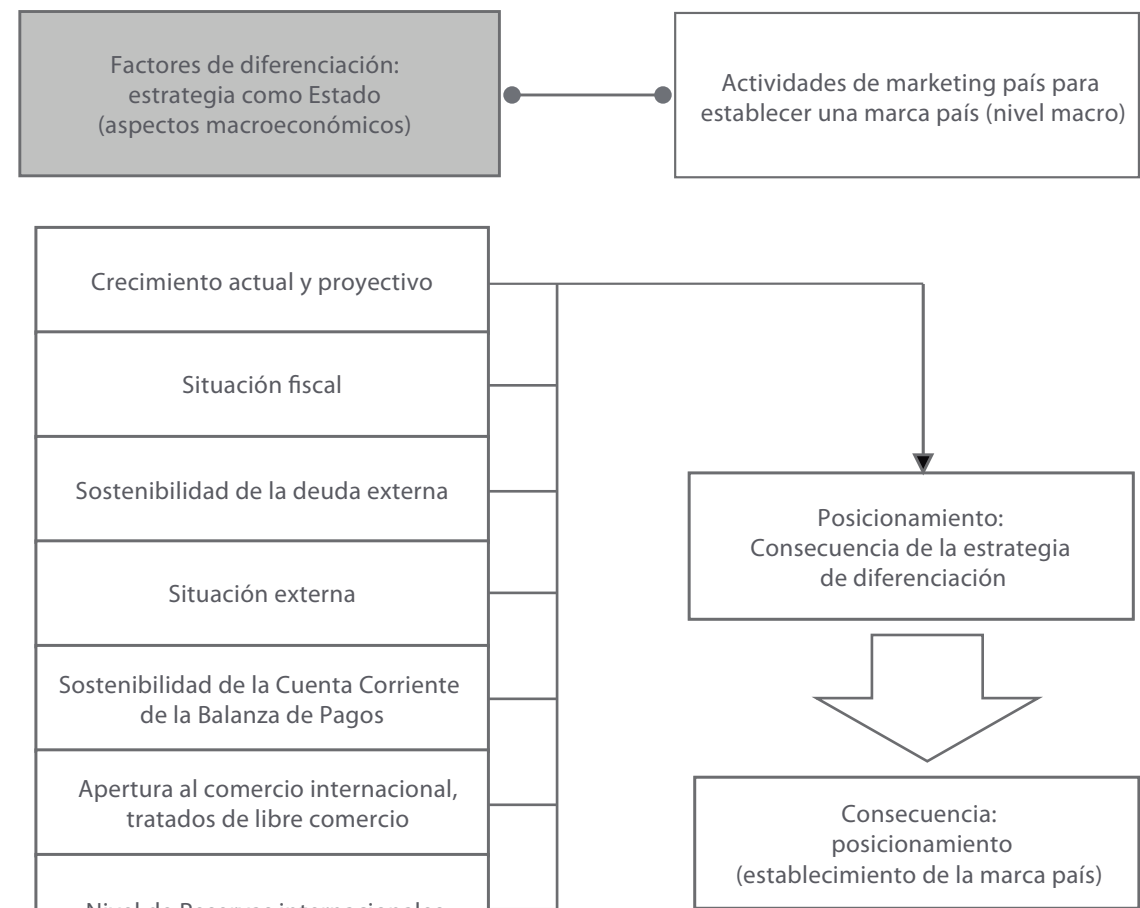

Fuente: elaboración del autor, basado en información de Pacific Credit Rating - PCR. 
atraídos por aquellos países que representen un menor riesgo en el largo plazo. Los siete indicadores citados pueden ser considerados como elementos de una mezcla de marketing que tienen por objetivo el posicionamiento de un país. Lo anterior explica que la marca país es un concepto que ayuda a atraer a los mercados objetivos de acuerdo con las posibilidades económicas, sociales, políticas, tecnológicas de cada país, dependiendo de la productividad que se pueda obtener; es decir, lo que se puede lograr con cada unidad de recurso asignado.

\section{El desarrollo de la marca país en el Perú}

Una de las consecuencias de la globalización es la menor rigidez de las fronteras, en la cual la competencia se hace más intensa, en especial en los países proveedores; hecho que motiva a que la competencia entre los países se haga más intensa. Los negocios internacionales tienen otra perspectiva en la cual la competencia y la capacidad de competir tienen un papel clave. De ahí viene la necesidad de los países de comenzar

Figura 2 .

Los distintos públicos de los grupos de interés

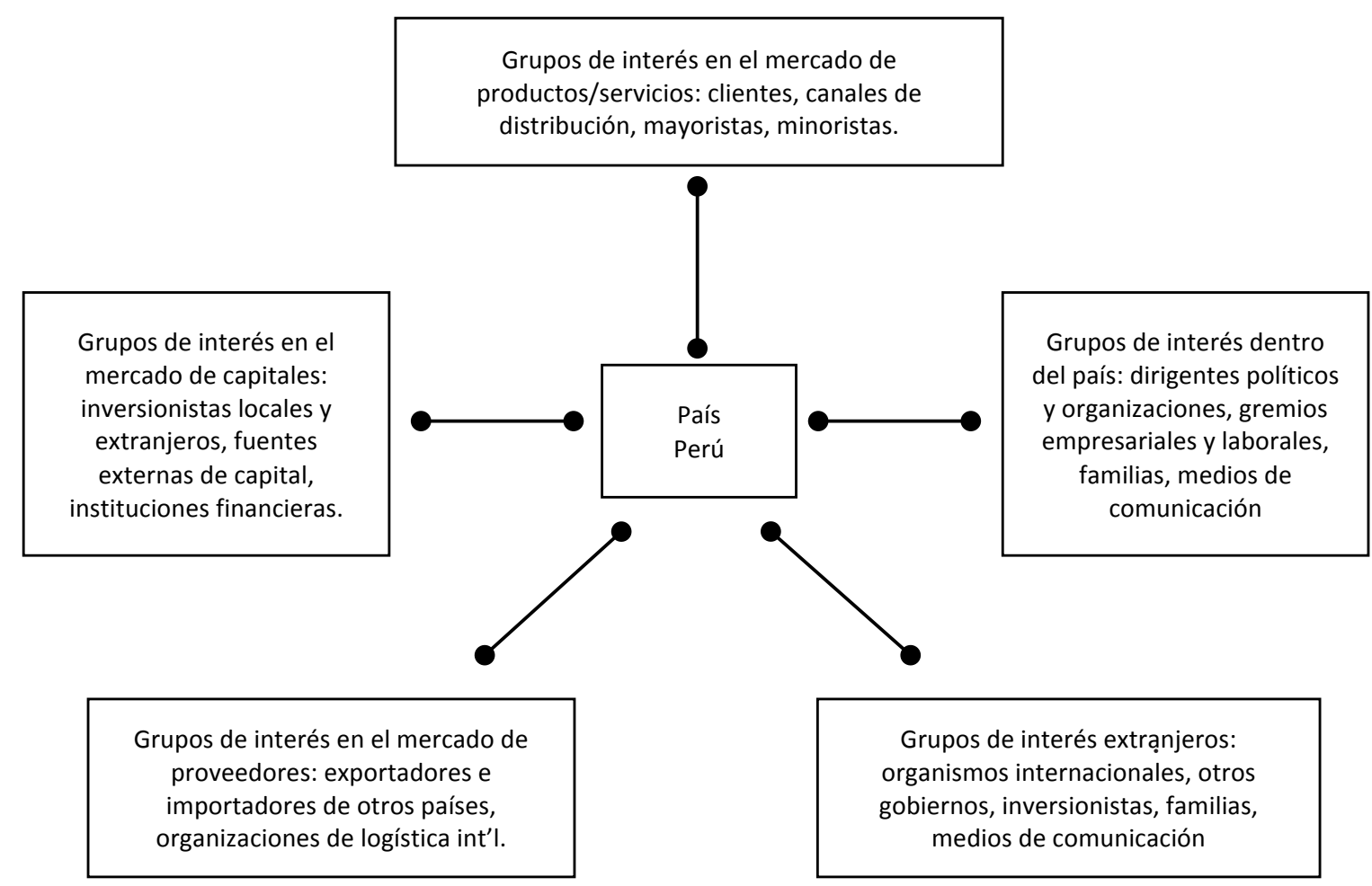

Fuente: elaboración del autor, con base en datos de Chiavenato-Sapiro (2011, p. 81). 
a diferenciar a través de acciones que permitan a sus mercados objetivo sentirse atraídos para invertir, para solicitar sus productos, hacer turismo o considerar la posibilidad de afincarse. La diferenciación que tiene como consecuencia el establecimiento de una marca da más seguridad a los compradores actuales y potenciales.

Los países tienen la necesidad impostergable de aceptar el desafío de la globalización, pues es la mejor manera de optar por un crecimiento económico sostenido. Cuando los países entienden esta interrelación, en cuanto al significado de fronteras, toman en cuenta que están compitiendo con otros países para atender a demandantes, así como el hecho de que tienen que obtener provecho de las actividades que realizan. Se tiene que tener una estrategia clara que contribuya a este proceso, que tenga como resultado un posicionamiento país sólido y sostenible.

De ahí viene la posibilidad de establecer una marca país como la suma de un conjunto de actividades de todos los grupos de interés locales o stakeholders 5 para llegar a ese objetivo. Establecer una marca país requiere de las consideraciones de todos y se debe tratar de aglutinar a los participantes como una tarea de tiempo y de todo aquello que lo relacione internamente. De algún punto tiene que partirse para tener una imagen consistente ante los diferentes clientes y países ofertantes que actúan en las relaciones comerciales internacionales. De lo que sí hay que estar seguros es de que todo se inicia en el interior de un país. El desarrollo de la estrategia de marca país se inicia dentro del mismo país.

Perú está en un intento de querer establecer un inicio, porque se tiene conocimiento de que una marca (asociado a un posicionamiento establecido) no se genera de un día para otro, pues requiere de tiempo y de mucho esfuerzo, como es el caso de querer cambiar la conducta de producción: de productor de bienes básicos (commodities) a

5 Chiavenato y Sapiro (2011) los definen como personas grupos u organizaciones que con su participación, directa o indirecta, influyen en los resultados estratégicos obtenidos y en el éxito del negocio, con la esperanza de obtener frutos de esa contribución. productos con un mayor valor agregado. Una marca genera confianza en el usuario actual y potencial de un producto, y que el éxito depende en primer lugar de la capacidad de dirección, de la gerencia de un país. El esfuerzo por establecer el Perú como un producto de marca es un esfuerzo de tiempo atrás, como puede observarse en los logotipos de la figura 3.

Figura 3.

Logotipos utilizados para apoyar

la identificación de la marca país ${ }^{6}$
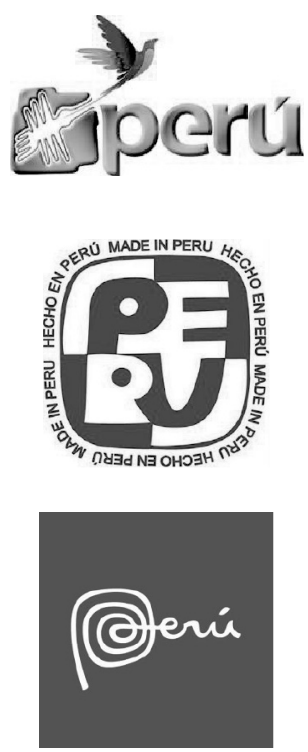

El compromiso, que exige un comportamiento determinado a los agentes internos, al ser planificado y por la dimensión del mismo, lleva a establecer unas normas escritas para lograr así cierta homogeneidad en aquellos que consideren actuar para su logro. En Perú existe un reglamento 7 para el uso de la marca país, el cual cita en el Artículo $4^{\circ}$ que "La Marca País es una herramienta de pro-

6 El primer logotipo fue tomado de http://divagacionesenelespacio-juank.blogspot.com/2011/05/marca-peru.html. El segundo logotipo expuesto fue publicado en http:// disenoperu.blogspot.com/2010/04/breve-recopilacion-demarcas-peru.html. El tercer logotipo fue tomado de http:// www.huaralenlinea.com/2011/05/10/marca-peru-en-elcorazon-de-todos-los-peruanos

7 Reglamento para el uso de la marca país. Recuperado de http://www.peru.info/solicitudes/public/reglamento.pdf. 
moción del Perú que tiene como objetivo impulsar los sectores turismo, exportaciones, inversiones y la imagen del país principalmente en los ámbitos de gastronomía, arte y cultura, deporte, educación y desarrollo de valores y autoestima nacional, a nivel nacional e internacional". Tal tarea implica - de acuerdo con lo que expone el reglamento en el artículo citado- un compromiso que tiene como finalidad:

1. La promoción del Perú y lo peruano.

2. La competitividad de las exportaciones peruanas.

3. El crecimiento del flujo de turistas hacia el Perú.

4. La atracción de inversiones hacia el Perú.

5. La mejora de la imagen del país en general.

En la actual campaña promocional de la marca país, Perú está constituida por la denominación Perú, escrita de acuerdo con el siguiente diseño característico, el mismo que puede observarse de diversos productos y servicios que tienen origen peruano.

Figura 4.

Logotipo que apoya el desarrollo de la marca Perú

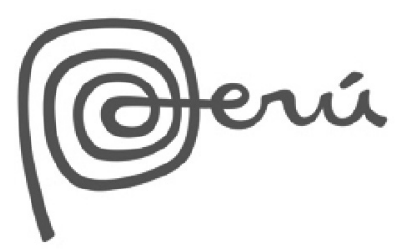

La experiencia internacional explica que lo que corresponde a la creación de una marca país debe partir de la idea de que lo que se busca es posicionar al país y que la marca se construye de manera articulada, y es asumida en compromiso e implementada por todos los agentes que forman parte del país en particular. Por el alcance que tiene la estrategia se convierte en política de Estado.
En términos de marketing internacional, se consideran las ideas de Philip Kotler (1998) en cuanto a las actividades que debe realizar un país para lograr posicionarse como marca país. El autor manifiesta como argumento necesario realizar previamente actividades de diferenciación que den como consecuencia el posicionamiento del producto. Lo esencial es que el esfuerzo permita al mercado objetivo obtener un valor superior a lo que otras alternativas le puedan ofrecer. En tal sentido, adecuándonos a una estrategia de marca país que sirva de soporte a una estrategia de largo plazo, ya que la solidez de la marca se relaciona con ese tipo de período, es recomendable lo siguiente:

1. Satisfacer las necesidades mejor que como lo hacen los otros países competidores.

2. Desarrollar productos de mayor calidad, tanto en el campo de los bienes, como en los servicios.

3. Ofrecer productos que el cliente considera como únicos.

4. Solucionar problemas que los competidores no pueden realizar por alguna limitación.

5. Reducir los costos al cliente, no solo los monetarios.

6. Ofrecer ventajas que sean visibles, que no exijan al mercado objetivo tener que buscarlas.

7. Ser innovador para fortalecer la ventaja que se logre.

Para crear clientes satisfechos las empresas deben gestionar su cadena de valor, así como el sistema de valor en la entrega, siempre centrándose en el cliente. Lo mismo deberían hacer los países si están considerando tener una marca dentro de una economía donde la competitividad es un requisito del crecimiento económico. Esto permite reflexionar en cuanto a las consideraciones de elaboración de una estrategia que a largo plazo ayude a establecer la marca país. En estas consideraciones está el riesgo relacionado con lo que citan Chavarría y Pacheco 
$(2007$, p. 3$)$ en cuanto a que se puede llegar a establecer una imagen de acuerdo con las características de los receptores, sea como país o como continente: cada receptor tiene una idea acerca de lo que es un país. Se debe considerar que este es un concepto y es intangible. Los países que tienen consolidada una marca país, para los receptores se identifican con un atributo; pero, pueda que ocurra - para otros países que consideran que es importante establecer una marca - que se relacionen con varios, y esto ocurre cuando la estrategia es fragmentada o no hay una única administración del proceso.

\section{EL COMERCIO INTERNACIONAL DEL PERÚ}

A $2011^{8}$, la economía peruana muestra un periodo de alto dinamismo, cerrando el año con un crecimiento de 6,9 por ciento. No obstante, a lo largo del año la tasa de crecimiento mostró una mayor volatilidad respecto al año anterior, tanto por el temor de una recaída de la economía mundial, sustentada a su vez en la crisis de deuda que atraviesan algunos países del sur de Europa, como por la incertidumbre propia de todo proceso electoral. La demanda interna creció 7,2 \% en 2011, luego de registrar un crecimiento de 13,1\% el año anterior. La tasa alcanzada en el año superó el promedio de la década, que fue de $6,8 \%$.

En el caso de los productos no tradicionales (PNT), en 2002 los productos agropecuarios ocuparon la segunda posición por monto de exportaciones por detrás de los productos textiles. En ese año era el 24,4\% de los PNT; en 2009, cuando pasaron a ocupar el primer lugar llegó a ser el $29,5 \%$. En 2011, Ilegan al 27,9\%, aportando US\$ 2830 millones. Hay que considerar que en 2002 los productos tradicionales (PT) representaban el 69,6 \%; a fines de 2011 llegaron al 77,5 \%, lo que representa US\$35.837 millones, cifra que se logra como consecuencia de los precios en los commodities minerales.

$8 \quad$ Elaborado considerando lo expuesto en la Memoria Institucional del Banco Central de Reserva del Perú, 2011.
Las exportaciones de bienes y servicios crecieron $8,8 \%$ debido a los mayores envíos de productos no tradicionales que aumentaron $20,2 \%$ en términos de volumen. Dentro de estos últimos gráfican los despachos de productos agropecuarios, pesqueros y químicos, en tanto que en el interior de los tradicionales destacaron las mayores exportaciones de café y harina de pescado.

La economía mundial registró una desaceleración importante durante 2011 , la cual reflejaba principalmente la evolución de las economías desarrolladas. Estados Unidos tuvo una débil recuperación del consumo, la Eurozona enfrentó una crisis de deuda y Japón se vio afectado por un sismo que interrumpió temporalmente la cadena de suministros. También influyó el alza en el precio del petróleo por la crisis política en los países árabes. Así mismo, las economías emergentes registraron una desaceleración, aunque continuaron creciendo a tasas elevadas. La crisis en la Eurozona generó también una fuerte volatilidad en los mercados financieros. Las tasas interbancarias en dicho bloque se elevaron, el dólar se apreció respecto al euro y la demanda por activos seguros, como los bonos del tesoro estadounidense, se incrementó.

Los principales socios comerciales del Perú continúan siendo Estados Unidos y China, los que representaron cerca de un tercio del comercio externo de bienes. Sin embargo, la participación de Estados Unidos disminuyó en 3,7 puntos porcentuales por la menor demanda, representando 13\% del total comerciado. Al mismo tiempo, aumentó la participación de otros mercados como Asia, Países Andinos y Mercosur. En los últimos diez años, las exportaciones de productos agropecuarios han crecido a una tasa promedio anual de $18 \%$, con lo cual el valor exportado de 2011 fue cuatro veces mayor al de 2002. Este dinamismo refleja el aumento de los volúmenes embarcados de uvas frescas, paltas frescas, mangos frescos, espárragos, paprika y alcachofa en conserva, entre otros productos.

La estrategia de establecer una marca país debe tener consecuencia en la demanda de los PNT, pues por su propio carácter llegan al consumidor individual, a través de canales de intermediarios en los 
Exportaciones de productos no tradicionales

(valores FOB en millones de US\$)

\begin{tabular}{|c|c|c|c|c|c|c|c|c|c|c|}
\hline & $\mathbf{2 0 0 2}$ & $\mathbf{2 0 0 3}$ & $\mathbf{2 0 0 4}$ & $\mathbf{2 0 0 5}$ & $\mathbf{2 0 0 6}$ & $\mathbf{2 0 0 7}$ & $\mathbf{2 0 0 8}$ & $\mathbf{2 0 0 9}$ & $\mathbf{2 0 1 0}$ & $\mathbf{2 0 1 1}$ \\
\hline Agropecuarios & 550 & 624 & 801 & 1.008 & 1.220 & 1.512 & 1.913 & 1.825 & 2.190 & 2.830 \\
\hline Legumbres & 271 & 308 & 380 & 452 & 563 & $\mathbf{7 1 3}$ & $\mathbf{7 9 8}$ & $\mathbf{7 3 9}$ & 864 & 980 \\
\hline Frutas & 89 & 111 & 140 & 178 & 259 & 311 & 412 & 461 & 585 & 903 \\
\hline Vegetales diversos & 69 & 66 & 75 & 100 & 108 & 135 & 180 & 173 & 225 & 280 \\
\hline Cereales y preparaciones & 40 & 41 & 47 & 53 & 66 & 77 & 121 & 124 & 126 & 170 \\
\hline Té, café, cacao y esencias & 38 & 47 & 86 & 132 & 116 & 151 & 217 & 185 & 196 & 264 \\
\hline Resto & 43 & 49 & 75 & 92 & 108 & 125 & 185 & 144 & 194 & 234 \\
\hline Pesqueros & 164 & 205 & 277 & 323 & 433 & 500 & 622 & 518 & 642 & 1.047 \\
\hline Textiles & 677 & 823 & 1.092 & 1.275 & 1.473 & 1.736 & 2.026 & 1.495 & 1.558 & 1.986 \\
\hline Maderas y papeles & 177 & 172 & 214 & 261 & 333 & 362 & 428 & 335 & 355 & 398 \\
\hline Químicos & 256 & 316 & 415 & 538 & 602 & 805 & 1.041 & 837 & 1.223 & 1.645 \\
\hline Minerales no metálicos & 68 & 74 & 94 & 118 & 135 & 165 & 176 & 148 & 251 & 487 \\
\hline Sidero-metalúrgicos & 222 & 262 & 391 & 493 & 829 & 906 & 909 & 569 & 918 & 1.128 \\
\hline Metal-mecánicos & 110 & 99 & 136 & 191 & 164 & 220 & 328 & 366 & 394 & 464 \\
\hline Otros & 33 & 45 & 58 & 70 & 89 & 107 & 121 & 93 & 110 & 145 \\
\hline Total PNT & $\mathbf{2 . 2 5 6}$ & $\mathbf{2 . 6 2 0}$ & $\mathbf{3 . 4 7 9}$ & $\mathbf{4 . 2 7 7}$ & 5.279 & 6.313 & $\mathbf{7 . 5 6 2}$ & $\mathbf{6 . 1 8 6}$ & $\mathbf{7 . 6 4 1}$ & 10.130 \\
\hline
\end{tabular}

Fuente: BCRP y Superintendencia Nacional de Administración Tributaria.

Figura 5.

Los mercados en la estrategia marketing país/marca país

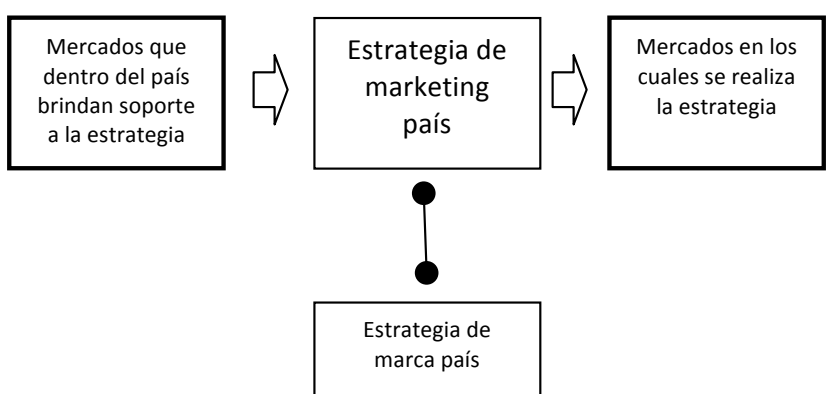

Fuente: elaboración de los autores. que ponen en relieve el origen del producto mientras que los commodities tienen un segmento objetivo diferente: el mercado corporativo. Ambos mercados son importantes para la economía y la atención a ambos apoya el desarrollo de la marca país. Aunque la estrategia de marketing país implica atención a ambos mercados, también debe considerarse cuál de ellos tiene un mayor efecto multiplicador. La estrategia de marketing país, de la cual es parte la marca país, tiene señalados dos macromercados: el de individuos (ciudadanos que residen en el propio país, ciudadanos extranjeros, nuevos residentes que provienen del extranjero) y el corporativo (inversionistas, exportadores, importadores, organizaciones).

\section{La competitividad en el Perú}

\section{Qué es la competitividad}

Menciona Van der Horst (2006, p. 19) que la competitividad es un concepto abstracto que tiene 
múltiples definiciones aceptadas y que es motivo de preocupación, planes y estrategias de naciones, gobiernos y empresas de todo el mundo, y ante la ausencia de ella pueden perder oportunidades por la conquista de los mercados internacionales. Para algunos, la competitividad es el resultado del entorno macroeconómico donde se desenvuelven las compañías e industrias, que se ve afectado por las tasas de interés y de cambio, y los niveles de déficit gubernamental. Otros sostienen que la competitividad se logra en función de la relativa abundancia y bajos costos de la mano de obra de que se disponga. También hay quienes la relacionan con los recursos naturales del país o con el tipo de políticas gubernamentales. Hay diferentes formas de interpretar este concepto. Lo que se sabe es que para todo país o empresa es necesaria.

El Consejo Nacional de la Competitividad (CNC), define la competitividad (2012, p. 8) "como la capacidad de un país para competir con otros". Cuando se establece este Consejo a través del Decreto Supremo 024-2202-PCM se menciona que se crea como una comisión de coordinación de asuntos específicos de la Presidencia del Consejo de Ministros (PCM) encargada de desarrollar e implementar un Plan Nacional de Competitividad con el objeto de mejorar la capacidad del Perú para competir en el mercado internacional. Como institución se considera como un ente de articulación intersectorial que en el corto, mediano y largo plazo busca lograr mejoras significativas en el ámbito de competitividad.

Acerca de lo que implica la competitividad hay diferentes opiniones. En muchas de ellas está la consideración hacia Porter (1996) como uno de los que más ha contribuido a la consolidación de tal concepto e incluso ha desarrollado una serie de medidas para determinar el nivel de competitividad y su aplicación a una realidad determinada implica la relación con una marca. Se toma como inicio para este planteamiento el hecho de que cualquier suceso que ocurra dentro de un país afecta su estrategia de marca, así como todo aquello que esté relacionado con el país. El desarrollo de la marca país se corresponde con la competitivi- dad del país; la competitividad de un país no se encuentra fuera de sus fronteras sino que tiene que originarse dentro del país.

La competitividad de un país es un elemento influyente en la determinación de la marca país, de ahí que se deban considerar en la estrategia los factores que la componen y determinar el grado de influencia que cada uno tiene, así como la prioridad que deben tener en el tiempo, considerando las posibilidades presupuestarias del país en función de los objetivos nacionales. La competitividad considera a las empresas, pero también incluye al Estado y a la fuerza laboral. Los países que se consideran competitivos superan las barreras que se presentan a estos tres agentes, aspecto que posibilita a la fuerza laboral de un mejor sistema de educación y salud, alimentación y, a la comunidad en general, seguridad. La competitividad tiene aquí su sustento si se observan las estadísticas de los países que presentan mejores índices de competitividad. Así se establece la marca país.

La competitividad está determinada por la productividad, definida como el valor del producto generado por una unidad de trabajo o de capital. A nivel de naciones, Porter (1990) define competitividad como la habilidad de los países para crear valor agregado y aumentar el bienestar de la población. La interpretación del concepto habilidad, entonces, debe ser analizada para desarrollar competitividad y la consecuencia en el desarrollo de una marca país.

\section{El Plan Nacional de Competitividad}

Las tareas que un país asume para establecer una marca país son parte de un plan que tiene los objetivos claros y con el cual los agentes están comprometidos; es un esfuerzo de los sectores público y privado. El trabajo para posicionar una marca país está asociado - en su relación con el mercado objetivo - a la competitividad, que debe ser parte de los integrantes de una nación, en especial de aquellos que toman las decisiones de carácter político nacional. Con relación a lo anterior, Iglesias y Molina (2008, p. 122) exponen que: 
La estrategia marca país (EMP) es una iniciativa que corresponde en partes iguales tanto a los poderes públicos como privados, y que sólo con la colaboración entre ambos puede llegar al éxito. Para ello, la EMP ha de combinarse con los avances y transformaciones en el ejercicio y gestión del softpower ${ }^{9}$, la diplomacia pública - virtual y la noopolitik ${ }^{10}$ respetando que:

a) La EMP es una estrategia de frente continuo.

b) La cultura también cuenta a la hora de explicar y fundamentar el crecimiento y desarrollo económicos.

c) Los políticos, empresarios y sociedad civil han de mirarse cara a cara, buscando una colaboración leal y honesta.

d) Se ha de generar una imagen y discurso coherente sobre el país para la opinión pública del planeta.

e) La creatividad y el talento también son recursos naturales que hay que saber aprovechar, y la EMP es una de las oportunidades para ello.

Las ideas de Iglesias y Molina están relacionadas con lo expuesto por el Plan Nacional en cuanto a la competitividad, el cual en su parte introductoria menciona lo siguiente $(2005$, p. 1):

Este Plan entendido como el conjunto de acciones consensuadas que son necesarias que el Estado lleve a cabo para que las empresas puedan competir eficientemente, debe ser ejecutado de manera oportuna para que podamos enfrentar

9 Poder blando, en inglés softpower, es un término usado en relaciones internacionales para describir la capacidad de un actor político, como por ejemplo un Estado, para incidir en las acciones o intereses de otros actores valiéndose de medios culturales e ideológicos.

10 In political science Noopolitik from the Greek Noos (knowledge) and German Politik (politics) is the network -based geopolitics of knowledge- con éxito los retos que traen la apertura y los acuerdos comerciales internacionales que nuestro país viene impulsando decididamente.

En términos generales la mejora de la competitividad de las empresas pasa fundamentalmente por que puedan acceder a insumos, materias primas y bienes de capital a precios internacionales; el costo de la mano de obra tenga niveles comparables con los países de la región que son nuestros competidores en el comercio mundial y no existan sobrecostos en la economía.

El tema central para lograr la competitividad en las empresas, es el incremento de la productividad de todos los recursos, humanos y físicos.

De ahí que el Plan Nacional de Competitividad $(2005$, p. 6) exponga que tiene por finalidad "Contribuir al mejoramiento sostenible de la calidad de vida de la población peruana" y como propósito "Mejorar la competitividad de las empresas para su exitosa inserción en el mercado global para el desarrollo social". La meta es "un crecimiento sostenido y sostenible del PBI de $7 \%$ anual, revisando el desempeño y la meta al 2011. Al 2006 el Perú pasa de la ubicación 76 a la 50 en el Índice Global de Competitividad del Foro Económico Mundial, mejorando su ubicación. Al 2011, el Perú se ubica entre los primeros 30 países en el referido Índice, con mejoras en todos los años".

El Plan Nacional expone siete objetivos que se logran con determinadas estrategias y de los cuales se esperan resultados (logros). Desde un punto de vista amplio de marketing país, estas actividades son las que permitirían al Perú diferenciarse de otros países y así establecer una marca país. Lo anterior implica que se reconoce que hay otros países que han optado por acciones similares que repercutirán en el posicionamiento del país, y esto tiene consecuencias en sus actividades económicas y sociales. Cada estrategia se puede considerar como una actividad de marketing, en un sentido muy amplio. Los objetivos que propone el Plan son los siguientes: 
1. Fortalecimiento institucional: fortalecer la institucionalidad con un sistema público efectivo en sus resultados y eficiente en su costo, organizaciones privadas y de la sociedad civil que sean representativas y tengan capacidades fortalecidas, para promover un adecuado clima de negocios del país.

2. Política económica, mercados financieros y de capitales: fortalecer la institucionalidad para mejorar el clima de negocios del país a través de adecuadas políticas económicas, comerciales, fiscales, tributarias y laborales; además, mejorar la provisión y el acceso a recursos financieros y de capital.

3. Infraestructura: aumentar y mejorar la infraestructura física y la provisión de los servicios relacionados para la integración de mercados y el desarrollo empresarial.

4. Articulación empresarial: fortalecer las cadenas productivas y clústeres o conglomerados para promover el desarrollo regional.

5. Innovación tecnológica e innovación empresarial: aumentar la aplicación de conocimiento para mejorar la competitividad de la producción usando las herramientas que provee la ciencia, la tecnología y la innovación.

6. Educación: desarrollar competencias en los jóvenes y adolescentes para lograr su mejor desempeño en la sociedad peruana.

7. Medio ambiente: mejorar el aprovechamiento sostenible de los recursos naturales y la conservación del ambiente, promoviendo la eficiencia empresarial y su crecimiento comercial.

La evaluación de los logros determina el grado de avance para establecer una marca país. Los países que hoy se consideran que tienen marca y que para los demandantes (países compradores, consumidores) es una garantía han superado lo que propone el Plan. Por lo tanto, una estrategia sólida es una mezcla de condiciones que se pueden lograr, siendo para todo país un desafío por superar en el largo plazo. La marca se conquista con el tiempo, con acciones efectivas, eficaces y eficientes permanentes que superan las actividades promocionales (entre ellas la publicidad) lo cual no niega su importancia.

Con Ley 28552 del 23 de mayo de 2005 se crea el Sistema Nacional de Planeamiento Estratégico y el Centro Nacional de Planeamiento Estratégico (Ceplan), destinado a conducir y desarrollar la planificación concertada como instrumento técnico de gobierno y de gestión pública, orientador y ordenador de acciones necesarias para lograr el objetivo estratégico de desarrollo integrado del país. En tal sentido, a través del citado organismo se norma la finalidad, naturaleza, ámbito, relaciones, organización y las funciones de los órganos que lo conforman en el marco de la Constitución Política del Perú y la ley.

Desde el punto de vista de marketing país, al Centro Nacional de Planeamiento estratégico le corresponden las tareas de diseño, y son los ministerios y demás organizaciones públicas, en coordinación con instituciones privadas, los que deben hacer realidad lo planeado. Esto es lo que permite la sostenibilidad de la estrategia marca país.

\section{La competitividad en el Perú}

Vera Tudela (2011, p. 9) menciona que "La competitividad es definida por el Foro Económico Mundial (WEF, por sus siglas en inglés) como el conjunto de instituciones, políticas y factores que determinan el nivel de productividad de un país. En este sentido, el fortalecimiento de la competitividad es condición necesaria para el crecimiento económico sostenido y la prosperidad de los países". Entonces, la productividad es factor importante para ser competitivo. El Estado debe proponer acciones para mejorar la productividad que entonces puede convertirse en una barrera para la competitividad. La productividad es una consecuencia de varios factores. 
Además, Tudela expone que en la región, según el Reporte de Competitividad Global 2011-12 del WEF, Perú se ubica en el puesto siete entre 20 países (puesto 14 en 2007-08). Así mismo, cita que el Perú es el país que registra, junto con Brasil, el mayor avance en competitividad a nivel regional durante el último quinquenio, dado que evidencia una mejora de siete puestos. La competitividad del Perú, en el orden micro y macro, ha registrado significativos avances durante el último quinquenio. El desempeño positivo reciente de la competitividad nacional es consistente con el crecimiento económico registrado por el Perú durante la última década. Si bien el país registra avances recientes en competitividad, la mejora de la actual posición relativa de Perú demanda la aceleración de las reformas pendientes. Las oportunidades de mejora necesarias para continuar el avance de la competitividad del Perú, acorde a los estudios del Foro Económico Mundial y del Banco Mundial, incluyen la consolidación de las reformas en las siguientes áreas:

1. Fortalecer la institucionalidad del país, lo que incluye factores como estabilidad política, derechos de propiedad, solución de conflictos judiciales, entre otros.

2. Elevar la calidad de la educación básica y superior.

3. Reducir las brechas de infraestructura física (transporte, principalmente).

4. Incentivar la competencia en el sistema financiero.

5. Facilitar el desarrollo del mercado de capitales.

6. Fomentar la capacidad de adopción tecnológica y la inversión en I\&D.

7. Simplificar regulaciones para los negocios, como pago de impuestos, cierre de empresas, permisos de construcción $y$ leyes laborales de firmas medianas $y$ grandes.

Aunque las explicaciones que da Vera Tudela son limitadas, puesto que no explica el alcance de cada una de ellas para que de esta manera se pueda considerar la profundidad de las reformas necesarias para ser, como país, competitivos, son indicadores por considerar para saber cómo estos pueden afectar una marca país sostenible. Hay que tener siempre presente que una estrategia de marketing país lleva al establecimiento de una marca país sostenible. Además, cita indirectamente Tudela, la importancia de la productividad cuando menciona los aspectos de educación y tecnología.

Esto se entiende a nivel de Estado, motivo por el cual se crea el Consejo Nacional de la Competitividad, comisión de coordinación creada mediante Decreto Supremo 024-2002-PCM y adscrita al Ministerio de Economía y Finanzas en diciembre de 2009. El Consejo tiene las siguientes funciones en materia de competitividad:

1. Detecta barreras y define prioridades estratégicas.

2. Impulsa y realiza el seguimiento de reformas transversales.

3. Articula sectores (público, privado y académico).

4. Orienta y provee información.

5. Evalúa las políticas de competitividad con su implementación.

En cuanto a los sectores donde se debe concentrar Perú para mejorar los niveles de competitividad está la propuesta de García-Vega (2011), que expone en su artículo acerca de la competitividad, que esta debe sostenerse en cinco sectores: minería, agroindustria, textil, turismo y gastronomía. Cita que "El objetivo estratégico de la propuesta sería mejorar la competitividad del país, lo cual se puede medir con el avance del Perú en los rankings expuestos en este documento. Las estrategias para ello están relacionadas con aspectos en los que el Perú debe mejorar y en algunos en los cuales se encuentra en buenas condiciones" (p. 112).

Seisdedos ${ }^{11}(2006$, p. 4) propone que el marketing de un país requiere de un proceso mental

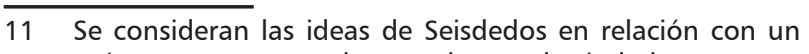
país, ya que expone el autor el tema de ciudades. 
abierto, con ausencia de pensamientos cortoplacistas, de modo que no se convierta en algo decorativo. Por lo tanto, debe considerarse que la actuación competitiva y que puede ser aplicada por el Perú debe tener en cuenta las actividades siguientes:

1. Este proceso vertiginoso da sus primeros pasos con la inclusión de sus productos en las campañas de marketing cuando se percibe que esta inclusión puede resultar positiva.

2. Paralelamente, y ya desde el lado público, se inician campañas de protección del mercado doméstico que tratan de poner en valor los atractivos de determinadas ciudades, regiones o Estados con este objetivo principal, más o menos encubierto.

3. Esta inicial implicación de los gobiernos locales pronto lleva a su extensión a dos nuevos campos que han resultado tremendamente expansivos: el turismo y la agricultura que requerirán de unas actuaciones más sofisticadas y coordinadas con nuevos agentes implicados.

4. En el turismo, la analogía con el sector empresarial es clara: el turista es el comprador y el producto, el país (Ilamado destino y que abre la puerta al marketing de destinos turísticos).

5. Respecto a la agricultura, también aparece una conexión muy clara entre el producto y el lugar donde es producido; esta conexión da sentido a que la promoción del país impacte positivamente sobre la imagen del producto.

6. La percepción de la importancia de la imagen de un país se abre a un nuevo campo: la atracción de inversiones, sea extranjera o en competencia con otros países. Muchos países tienen sus agencias de desarrollo económico, como es el caso de Proinversion, creada para tratar de atraer localizaciones de nuevas empresas e inversiones.
7. Pronto se percibe que la promoción de las exportaciones es un complemento perfecto para las campañas orientadas, tanto a atraer nuevas inversiones, como a proteger el mercado doméstico, con lo cual se busca la preferencia de los consumidores locales por los bienes y servicios generados en el propio país.

8. Una última tendencia es la realización de campañas orientadas a la atracción de nuevos residentes. Esta nueva generación de promoción de ciudades pasa por atraer mano de obra cualificada. Tratar de animar a emigrantes con altas cualificaciones a volver a su casa y contribuir a la economía local es una alternativa para considerar.

\section{LA MARCA PERÚ}

\section{El papel de los agentes económicos en el establecimiento de la marca}

El papel de los stakeholders es importante, especialmente el de los agentes internos ya que ellos tienen que apoyar la creación de condiciones para que una marca país se consolide. Considerando que son las fuerzas internas las que permiten generar la competitividad de un país y por tanto tener la posibilidad de establecer una marca, un país posicionado con características diferentes y superior a otros países con similar oferta. Los países están en la búsqueda de establecer su marca, pero esto no significa que tendrán éxito; no basta con un extenso programa promocional (lo que incluye publicidad, participación en ferias internacionales, actividades de relaciones públicas), la estrategia de marketing país debe ser que esto sea posible en el largo plazo.

Vale la pena considerar las siguientes razones que expone Seisdedos (2006, p. 6), por las cuales puede fracasar la estrategia de marketing internacional en cuanto a establecer una marca país, si hay una concentración en un logo y una intensa campaña promocional: 
1. Falta de conexión con las estrategias de desarrollo económico del país.

2. Ausencia de voluntad política suficiente para ser tomados en serio y mantenidos en el largo plazo.

3. Restricción de inversión en medios suficiente para cruzar el umbral de notoriedad requerido en una sociedad sobresaturada de estímulos comunicativos.

4. Limitaciones de conocimiento en cuanto a la audiencia a la que se dirigen los esfuerzos.

5. Desconocimiento de la percepción original de la imagen del país de la que son parte diferentes colectivos implicados.

6. Falta de coordinación y voluntad entre los diversos stakeholders.

En todo este complejo sistema de competencia y competitividad, los investigadores tienen como punto común la trascendencia, lo que implica ir más allá de una coyuntural, por un determinado Gobierno. De lo contrario, el esfuerzo por establecer una marca país se convierte en un compromiso que implica modificaciones estructurales, es un compromiso de trascender más allá de un logotipo o compañas promocionales. Por su parte, Villa Araque (2009), al realizar su investigación respecto a Colombia, expone lo siguiente:

Cualesquiera que sean los objetivos para emprender un proyecto de imagen es importante concebir la estrategia de marca, no como un mero instrumento de comunicación, sino como una política continua que sea capaz de adaptarse a los cambios coyunturales y a la realidad del país, y que perdure a pesar de la transición de gobiernos y de la implementación de nuevos programas. $\mathrm{Tal}$ vez, este es el desafío que tienen sobre todo los proyectos de marca de los países latinoamericanos actualmente (p. 48).
Los agentes económicos en el Perú al ser parte del establecimiento de una marca país pueden considerar lo que expone Abó (2010, p. 4) en cuanto a que "todos los países están interesados en atraer clientes, pero al igual que una empresa comercial, deben definir su público objetivo". En ese sentido, es importante lo que Abó recomienda en cuanto a que los países deben segmentar entre tres grupos de clientes: personas y negocios, congruentes con la visión de país definida; personas y negocios que son aceptables, pero no constituyen el target definido; personas y negocios que deben ser evitados. Para Abó un país puede intentar atraer cuatro tipos de grandes mercados:

1. Visitantes. Se dividen en dos tipos: visitantes de negocios y turistas. Como en cualquier plan de marketing, al país le conviene buscar segmentos diferenciados dentro de este gran mercado. Debe decidir si atraer una gran masa de turistas con bajo gasto o una pequeña masa con gran gasto; de la región o de extra región; jóvenes, adultos o familias completas; apostadores, grandes convenciones de negocio, ferias industriales o pequeños foros, etc.

2. Residentes y trabajadores. Otro importante gran mercado objetivo por atraer son los residentes y trabajadores. En este caso, Abó pone como ejemplo a Alemania y Francia países que se esforzaron por atraer durante varios años trabajadores no calificados de Turquía, Argelia y Marruecos. Países con edades promedio altas como Suecia y Austria trabajan en atraer personas jóvenes. Estados Unidos atrae utilizando sus universidades y grandes corporaciones a personas de todo el mundo con el más alto grado de preparación.

3. Negocios e industrias. Un tercer gran grupo son las industrias y los negocios. El objetivo final de este grupo suele ser la generación de empleo. En el pasado 
los países típicamente intentaron atraer industrias pesadas mientras que la tendencia actual es atraer negocios de servicios y compañías de alta tecnología. Este mercado es el más complejo de segmentar correctamente por dos razones: la cantidad de variables es mayor para negocios o industrias que para personas; segundo, es muy difícil rechazar una oportunidad de instalación de una industria declarada no deseable para el país por no encajar con la visión definida. Sin embargo, un error en este aspecto puede resultar carísimo para la imagen exterior de un país, especialmente si la industria es altamente contaminante o afecta al medio ambiente en general y un país contiene como fundamentos de su visión la creación de imagen de "país natural".

4. Mercados de exportación. Un cuarto mercado objetivo es el de las exportaciones. Son pocos los grandes países exportadores de productos de valor agregado que no hayan creado una marca fuerte. Italia disfruta de una gran imagen en productos de moda de alta calidad; la etiqueta Made in Japan logra de por sí confianza en el consumidor de automóviles y productos electrónicos. Crear una marca es un proceso complejo, costoso y de largo aliento, pero una vez que se ha conseguido para algún producto en particular es fácilmente transferible a otros de características similares. Una agencia de promoción de exportaciones de un país o región puede contribuir de varias formas: otorgando créditos blandos o subsidios, ofreciendo asistencia técnica, fomentado ferias de los productos locales en el exterior $y$, principalmente, atendiendo veloz y diligentemente a empresas con interés en radicar inversiones en él a fin de fabricar productos para la exportación.
Si relacionamos las ideas de De Elizagarate (2008, p. 89) de marketing de ciudades, los países que deciden desarrollar una marca país deben disponer un plan de marketing que se relacione con un proceso de entrega de valor en diferentes fases. La primera de dichas fases es la elección de valor por ofrecer sus diferentes mercados objetivo, como a los propios ciudadanos y a los inversionistas privados (locales y extranjeros), agencias del Gobierno, empresas, turistas extranjeros y nuevos residentes. Para abordar esta tarea es conveniente contar con un sistema de información que monitoree todas estas relaciones, ya que así se logra estar en condiciones para atender a los diferentes mercados y fortalecer el posicionamiento buscado. En todo esto, se tienen en cuenta agentes que son: 1. soporte de la estrategia y 2 . que se realiza la estrategia de marketing (figura 6).

Hay diversas opiniones acerca de considerar los mercados que deben ser atendidos por la estrategia de marketing país, de la cuales parte una estrategia de marca país que a su vez es solo una de las estrategias que se desarrollan para el posicionamiento del país. Todos los mercados son importantes, pero quien da sostenibilidad a la estrategia son los agentes de soporte, como es el caso de los ciudadanos que residen en el país, las empresas que abastecen el mercado local y el extranjero, así como los agentes del gobierno, en la expresión de la burocracia.

\section{Actividades para desarrollar la marca país de un país}

El desarrollo de una marca país es una tarea compleja. Ocurren hechos que en el interior del país no se pueden controlar o que son de poca previsibilidad; aspectos políticos, sociales, económicos, culturales. Las estrategias de marca país de cada país tienen un punto en común: buscan atraer al mismo público, de ahí que los factores que permiten diferenciar son claves para tomar ventaja. Estas diferencias deben considerarse como atributos únicos y con los cuales se tiene ventajas sobre otros, hecho que debe ser percibido así por este 


\begin{tabular}{|c|c|}
\hline $\begin{array}{c}\text { Mercados } \\
\text { soporte de la } \\
\text { estrategia }\end{array}$ & $\begin{array}{c}\text { Mercados en los } \\
\text { cuales se realiza } \\
\text { la estrategia }\end{array}$ \\
\hline
\end{tabular}

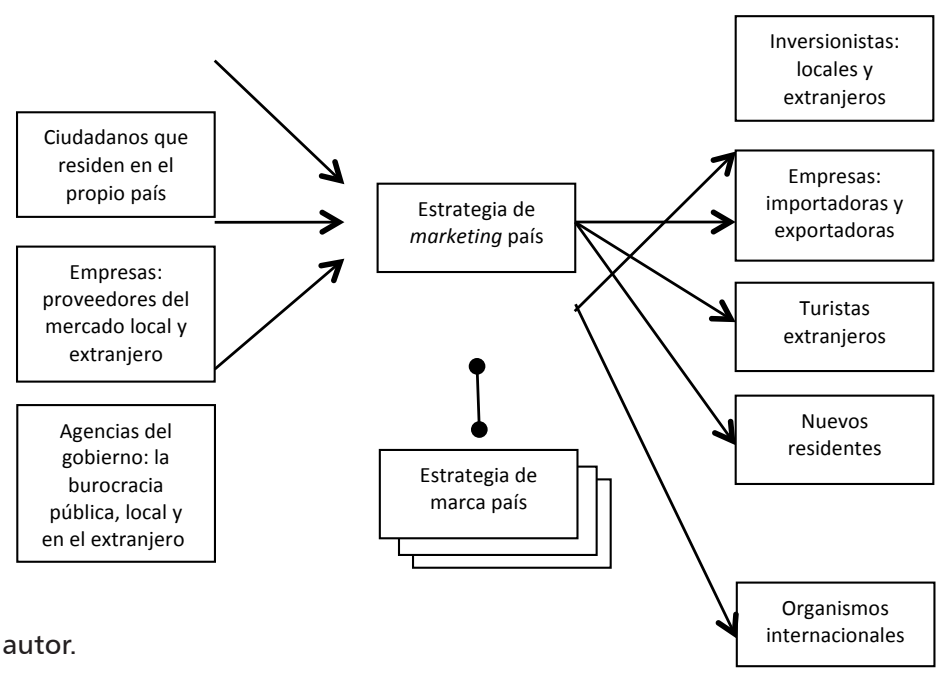

Fuente: elaboración del autor.

público objetivo, y motivo por el cual su promoción es importante para que tenga conocimiento y se pueda comprobar. El uso del marketing por países, expresado a través de una política nacional, es algo novedoso entre los países latinoamericanos; ahora es un esfuerzo planificado y no se genera espontáneamente en algún país.

Se citan a continuación los siguientes ejemplos en los que se exponen el logotipo y la justificación o razón para establecerse como marca.

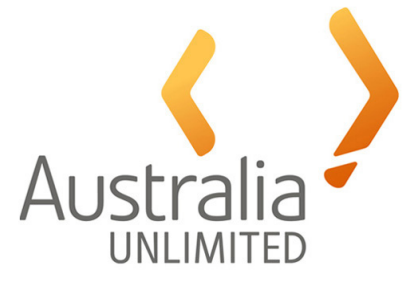

Australia $^{12}$ : Australia Unlimited is a nation brand that was developed in response to global research that demonstrated our global reputation

12 Publicado en http://www.australiaunlimited.com was based more on our physical attributes than our intellectual ones.

The Brand is part of a broader program called Building Brand Australia, which is funded by the Australian Government, to enhance our international reputation.

\section{Argentina}

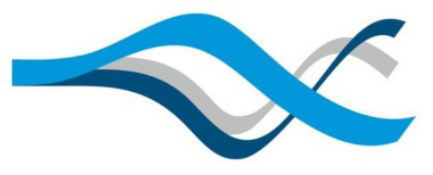

Argentina ${ }^{13}$ : abarca tanto el contexto internacional, como nacional y debe servir como impulsora de las estrategias de marcas regionales, provinciales, municipales, sectoriales y privadas. Para ello, incluye un trabajo específico de acciones de vínculo con estas estrategias. Se articula con los diferentes organismos públicos, mixtos y privados relacionados con las exportaciones, el turismo,

$\overline{13}$ Publicado en http://www.marcapaisargentina.org/ 
las inversiones, la cultura y los servicios profesionales, y las asociaciones gremiales empresarias y de trabajadores; de esta manera, se pone a su servicio para la concreción fehaciente de los objetivos definidos en la misión.

La marca país para Argentina se construye a partir de factores diferenciales, creíbles y sostenibles en el tiempo, englobados en el concepto de diversidad; más concretamente, una "diversidad que crea valor". Así, turismo, bienes y servicios, cultura y sociedad del conocimiento conjugan los componentes esenciales del trabajo focalizado en obtener más inversión y prestigio internacional para el país, ambos traducidos en mejores oportunidades para todos los ciudadanos argentinos.

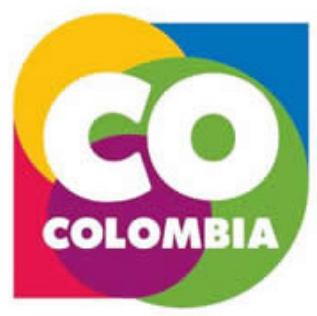

Colombia ${ }^{14:}$ la marca Colombia es un esfuerzo conjunto del Gobierno nacional y del sector privado para mostrarle al mundo el tesón, dedicación, trabajo y pasión con el que los colombianos han hecho de este el mejor país para vivir.

Echeverry y Rosker (2011) resumen, a través de la investigación que realizaron, lo imperativo que es para algunos países establecerse como marca. La investigación se basa en lo que realizan Argentina y Colombia; sin embargo, en lo que concluyen tiene validez para la tarea que han asumido otros países al respecto. Lo anterior lo explican los autores mencionados de esta manera:

Argentina y Colombia están haciendo esfuerzos por perfeccionar su marca país con la intención de cumplir tres grandes objetivos: atraer turistas, esti-

14 Publicado en http://www.colombia.co/ mular la inversión interna e impulsar las exportaciones. Otro cuarto objetivo para algunos países es atraer talento humano. Este nuevo objetivo permite a los países competir entre sí por atraer a estudiantes de educación superior y a empleados calificados (p. 8).

Los mismos investigadores consideran que la marca país tiene como objetivos adicionales contribuir a la estabilidad de la moneda, ya que ayuda a restaurar credibilidad internacional y confianza en los inversores, aumentar la influencia de las políticas internacionales, estimular el fortalecimiento de las asociaciones internacionales y promover las ventajas competitivas de un país. Los anteriores objetivos coinciden con la intencionalidad de cuatro países suramericanos que fueron incluidos en el estudio: Argentina y Colombia. El logro de esos objetivos requiere que los países adopten de manera consciente y responsable las actividades de marketing para establecer su marca país y puedan así competir eficazmente en el escenario global.

El trabajo de Ramos y Noya, en cuanto al establecimiento de una marca país y su relación con el riesgo país, presenta una exposición interesante acerca de cómo se inicia el proceso en Argentina: allí ese empieza por reconocer, luego de un análisis severo, lo que representa para la comunidad internacional, ya que ese es el mercado de un país orientado al comercio internacional. EI inicio del diseño de una estrategia, en relación con Argentina, puede ocurrir para todo país que así lo considere y lo que se expone a continuación es una muestra de esto:

A fines de 2001 y a lo largo de 2002, Argentina atravesó una de sus mayores crisis económicas y una importante devaluación de su moneda. David Ratto, 3 en una columna del periódico La Nación, advertía que en ese momento Argentina era conocida en el exterior más por sus problemas que por sus virtudes. "Contamos con imágenes nostálgicas o con 
iconos de viejos tiempos porque la real imagen que damos hoy es la de riesgo país", sentenciaba. Por su parte, Ricardo Vanella denunciaba que "es un sinsentido seguir ignorando este tema [...] si a todo ello agregamos que ese índice fatal que estamos observando cotidianamente con tanta angustia, llamado 'riesgo país', también él está compuesto en gran medida por cuestiones de percepción y de imagen, cabe preguntarse hasta qué punto y por cuánto tiempo más la dirigencia nacional [...] puede seguir ignorando un tema tan estratégico como es un plan de comunicación a nivel internacional [...]" (Ramos y Noya, 2006, pp. 4, 5).

En relación con Colombia, los mismos autores expresan de qué manera esto tiene que convertirse en una política de Estado e involucrar muchos más factores donde el comercio sea la parte visible:

El principal problema de la imagen de Colombia es la asociación con la violencia en varias formas: narcotráfico, guerrillas, cuerpos paramilitares, etc. En el país hay conciencia de las repercusiones internacionales. Tokatlián, en un artículo de El Tiempo de 2002, ya llamaba a reflexionar sobre la necesidad de proyectar una imagen en el exterior que corrigiese el estereotipo, aunque supeditaba la cuestión a otra de carácter interno: la identidad colombiana. Sólo "una buena identidad nacional hace posible una buena política exterior". En el caso de Colombia, sólo un "nuevo modelo de negociación" permitiría superar la guerra permanente y proyectar una 'identidad robusta' para poder mejorar la imagen y ganar respecto en el concierto de las naciones (Ramos y Noya, 2006, pp. 4, 5).

\section{Conclusiones}

1. La estrategia marca país es una actividad que está siendo adoptada por una diversidad de países, en el entendimiento de que hay una mayor competencia entre países y que los países demandantes (incluye inversionistas, organizaciones, visitantes, residentes) a través de la misma exponen de manera más clara su oferta de bienes, servicios y personas. Es parte de una estrategia de marketing país.

2. Para establecer una marca país consolidada es conveniente que el riesgo país disminuya, siendo para ello necesario tomar en cuenta los indicadores que establecen las diversas empresas calificadoras de riesgo, en especial cuando se busca atraer inversionistas. Pero estos no son todos los factores por considerar. Sin embargo, todos ellos están relacionados a acciones de largo plazo, que están relacionados a cambios estructurales y compromiso de todos los actores de la sociedad.

3. Las teorías de comercio internacional de alguna manera están relacionadas con el establecimiento de una marca país, en consideración a los productos o negocios que se realizan en una economía abierta. El tiempo ha añadido a estas teorías la aplicación del marketing, que con sus instrumentos busca que los países obtengan ventaja de sus relaciones comerciales internacionales.

4. La estrategia de marca país es consecuencia de una serie de actividades de diferenciación; es decir, previo a establecer una marca se tiene que realizar o programar una serie de actividades que den como resultado lo que se busca a través de la marca país. A nivel de marketing país, se está ante un intento más de posicionar al Perú, notándose esta vez que hay un mayor esfuerzo en el que participan diversos agentes.

Finanz. polit. econ., ISSN 2248-6046, Vol. 6, No. 1, enero - junio, 2014, pp. 115 - 140

Edición Especial - Economía Regional 
5. Aunque el actuar de los agentes no está claro, en cuanto a su participación y metas, es decisivo para ponerse en la base de la competitividad como país. En Perú el esfuerzo es incipiente y es importante que dé resultados que no se manejen de manera más abierta para así conocer los avances. Lo que sí es visible son los resultados macroeconómicos que se publican a través de las instituciones públicas, pero hay otros resultados que no son transparentes. La información pública en esta estrategia es básica porque así se reconocen los esfuerzos adicionales que hay que hacer como país.
6. La producción local tiene diversos mercados en el exterior. Los productos tradicionales están relacionados con el mercado de los grandes inversionistas, mientras que los no tradicionales, con el mercado de pequeños y medianos inversionistas, así como con distribuidores y consumidores; aspecto que debe relacionarse con la coyuntura. Los productos no tradicionales (commodities) corresponden más a acciones coyunturales, mientras que los otros tienen una menor influencia, en especial los relacionados con la agricultura.

\section{REFERENCIAS}

1. Abó, J. (2010). Un modelo conceptual para generar una marca país. Recuperado de http:// webcache.googleusercontent.com/search?q=cache:L3oe05ZydPEJ:espectadornegocios.com/ xcore/components/i/\%3Ffn\%3Ddwn\%26i a\%3DLi4vLi4vLi4vbWVkaWEveGNvcmUvTW FyY2FfUGFpc19VbiBtb2RlbG8gY29uY2V̄ wdHVhbCBfQWJvXy5wZGY\%3D+\&cd=2\&h $\mathrm{l}=\mathrm{es}-419 \& \mathrm{ct}=\mathrm{clnk} \& \mathrm{gl}=\mathrm{pe}$

2. Banco Central de Reserva del Perú (2011). Memoria 2011. Lima: Banco Central de Reserva del Perú.

3. Chavarría, M. y Pacheco, M. (2007). La marca país como un instrumento para contribuir al proceso de internacionalización de las PYMES. San José: Universidad Estatal de Distancia.

4. Chiavenato, I. y Sapiro, A. (2011). Planeación estratégica: fundamentos y aplicaciones (2da. edición). México: McGraw Hill.

5. Czinkota, M. y Ronkainnen, I. y Moffett, M. (2006). Negocios Internacionales (7ma edición). México: Thomsom Editores S.A.

6. Consejo Nacional de Competitividad (2012). La Agenda de Competitividad 2012-2013. Lima: Consejo Nnacional de Competitividad.

7. Consejo Nacional de la Competitividad (2005). Plan Nacional de Competitividad: buscando la inserción exitosa del Perú en el mercado global. Documento del Consejo Nacional de Competitividad. Lima, Perú.

8. De Elizagarate, V. (2008). Marketing de ciudades: estrategias para el desarrollo de ciudades atractivas y competitivas en un mundo global. Madrid: Ediciones Pirámide.

9. Echeverri, L. y Rosker, E. (2011). Estrategias y experiencias en la construcción de marca país en Argentina y Colombia. XVI Congreso Internacional de Contaduría, Administración e Informática. México: Universidad Nacional Autónoma de México.

10. Echeverri, L. y Rosker, E. (2011). Lecciones y experiencias en la construcción de marca país en Canadá y Colombia. Borrador de Administración, 52.

11. García-Vega, E. (2011, enero-abril). Competitividad en el Perú: diagnostico a priorizar y lineamientos a seguir para el período 2011-2016. Revista Globalización, competitividad y gobernabilidad, 5(1), 112-141. 
12. Iglesias Onofrio, M. y Molina Rabadán, D. (2008). La estrategia marca país en la sociedad informacional: los casos de España y Ecuador. Revistas Historia actual [en línea], 16, 109-126.

13. Interbrand (2011). Marca Interna Marca externa como catalizador del cambio: conclusiones del estudio. Madrid: Asociación de marketing de España.

14. Kotler, P., Jatusripitak, S. y Maesincee, S. (1998). El marketing de las naciones: una aproximación estratégica a la creación de la riqueza nacional. Barcelona: Ediciones Paidós Ibérica S.A.

15. López Da Silva, E., Bravo, E, et al. (2010). El efecto de la imagen marca país en el proceso de decisión del consumidor. Universitat Politècnica de Catalunya. Revista Intangible Capital, 334-344.

16. Ministerio de Comercio exterior y Turismo (2012). Reglamento para el uso de la marca país. Lima: Mincetur.

17. Otero, M. (2011). Imagen empresarial y valor de la marca país. Revista Uno, 2, 17-18.

18. Pacific Credit Rating Publicado (PCR) (s.f.). Recuperado de http://www.ratingspcr.com/ archivos/publicaciones/SECTORIAL_PERU_SOBERANO_201012.pdf

19. Porter, M. (1990). Competitive Advantage of Nations. New York: The Free Press.

20. Porter, M. (1996). Ventaja Competitiva: creación y sostenimiento de un desempeño superior (12ava reimpresión). México: Compañía Editorial Continental S.A.

21. Revista de la Universidad San Ignacio de Loyola (s.f.). Registro país. ¿Qué es? Recuperado de http://www. usil.edu.pe/revistas/pdf/aet/mayo2005/PAG05.PDF

22. Ramos, M. y Noya, J. (2006). América Latina: del riesgo país a la marca país y más allá. Madrid: Real Instituto Elcano de Estudios.

23. Seisdedos, H. (2006). Creando marca de ciudad: principios básicos. Madrid: Instituto de empresa.

24. Van der Horst Álvarez, A. (2006). Desafío global para el reto local. Santo Domingo: Editora Corripio.

25. Vera Tudela, R. (2011). Competitividad en el Perú: situación y agenda pendiente. Revista Moneda, 149, 8-12.

26. Vilas, J.M. (2011). Marcas líderes y distribuidores: buenas prácticas de colaboración. Madrid: ESIC Editorial.

27. Villa Araque, P. (2009). Hacia una estrategia de marca país: Caso Colobia es pasión. Bogotá. Universidad Colegio Mayor de Nuestra Señora del Rosario.

28. Yagüez, E. (2001). La importancia de gestionar la marca país. Marca interna y externa como catalizador del cambio: conclusiones del estudio Q4 2011. Madrid: Asociación de Marketing de España. 